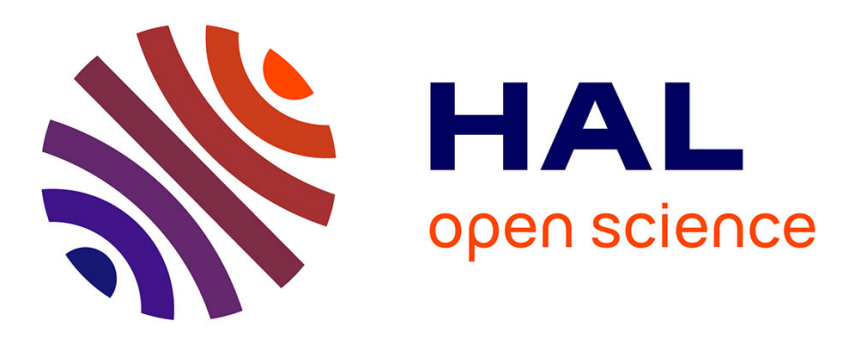

\title{
Linking NO2 surface concentration and integrated content in the urban developed atmospheric boundary layer
}

\author{
Elsa Dieudonné, François Ravetta, Jacques Pelon, Florence Goutail, \\ Jean-Pierre Pommereau
}

\section{To cite this version:}

Elsa Dieudonné, François Ravetta, Jacques Pelon, Florence Goutail, Jean-Pierre Pommereau. Linking NO2 surface concentration and integrated content in the urban developed atmospheric boundary layer. Geophysical Research Letters, 2013, 40, pp.1247-1251. 10.1002/GRL.50242 . hal-01058416

\section{HAL Id: hal-01058416 https://hal.science/hal-01058416}

Submitted on 26 Aug 2014

HAL is a multi-disciplinary open access archive for the deposit and dissemination of scientific research documents, whether they are published or not. The documents may come from teaching and research institutions in France or abroad, or from public or private research centers.
L'archive ouverte pluridisciplinaire HAL, est destinée au dépôt et à la diffusion de documents scientifiques de niveau recherche, publiés ou non, émanant des établissements d'enseignement et de recherche français ou étrangers, des laboratoires publics ou privés. 


\title{
Linking $\mathrm{NO}_{2}$ surface concentration and integrated content in the urban developed atmospheric boundary layer
}

\author{
E. Dieudonné, ${ }^{1,2}$ F. Ravetta, ${ }^{1}$ J. Pelon, ${ }^{1}$ F. Goutail, ${ }^{1}$ and J.-P. Pommereau ${ }^{1}$ \\ Received 12 November 2012; revised 5 February 2013; accepted 7 February 2013; published 27 March 2013.
}

[1] A statistical linear relationship between $\mathrm{NO}_{2}$ surface concentration and its integrated content in the atmospheric boundary layer (ABL) is established in urban conditions, using ABL depth as an ancillary parameter. This relationship relies on a unique data set including 20 months of observations from a ground-based UV-visible light spectrometer and from an aerosol lidar, both located in Paris inner city center. Measurements show that in all seasons, large vertical gradients of $\mathrm{NO}_{2}$ concentration exist in Paris developed $\mathrm{ABL}$, explaining why the average concentration retrieved is only about $25 \%$ of $\mathrm{NO}_{2}$ surface concentration. This result shows that the commonly used hypothesis of constant mixing ratio in the $\mathrm{ABL}$ is not valid over urban areas, where large $\mathrm{NO}_{x}$ emissions occur. Moreover, the relationship obtained is robust, and the studied area lacks of any particular orographic features, so that our results should be more widely applicable to pollution survey from space-borne observations. Citation: Dieudonné, E., F. Ravetta, J. Pelon, F. Goutail, and J.-P. Pommereau (2013), Linking $\mathrm{NO}_{2}$ surface concentration and integrated content in the urban developed atmospheric boundary layer, Geophys. Res. Lett., 40, 1247-1251, doi:10.1002/grl.50242.

\section{Introduction}

[2] Nitrogen dioxide $\left(\mathrm{NO}_{2}\right)$ surface concentrations have become necessary measurements of air quality in cities due to road traffic and industrial activities. However, in situ measurements are affected by dilution and reactivity in the atmospheric boundary layer (ABL), and a large number of observations is required to derive a representative emission budget over extended urban areas. This makes $\mathrm{NO}_{2}$ surface concentration measurements difficult to use to monitor nitrogen oxides $\left(\mathrm{NO}_{x} \equiv \mathrm{NO}+\mathrm{NO}_{2}\right)$ emissions. Moreover, not all cities are well equipped, particularly in developing countries, though they represent a growing part of $\mathrm{NO}_{x}$ emissions.

[3] Satellite observations provide information on $\mathrm{NO}_{2}$ vertically integrated content in the troposphere. Over polluted areas, this quantity is mostly related to the ABL, and better suited than surface measurements to account

${ }^{1}$ LATMOS/IPSL, CNRS/UPMC, Paris, France.

${ }^{2}$ Now at LMD/IPSL, CNRS/Ecole Polytechnique, Palaiseau, France.

Corresponding author: E. Dieudonné, LMD/IPSL, Ecole Polytechnique, 91128 Palaiseau Cedex 24, France. (edieudon@1md.polytechnique.fr)

(C)2013. American Geophysical Union. All Rights Reserved. 0094-8276/13/10.1002/grl.50242 for $\mathrm{NO}_{x}$ emissions. But the use space-borne observations to monitor air quality presently suffers from a limited horizontal resolution and temporal coverage (clouds, overpass time). The main problem is that no relationship has been proven to be reliably usable to deduce the surface concentration from the measured integrated content. Indeed, to our knowledge, no $\mathrm{NO}_{2}$ concentration profile has ever been measured over urban areas, though they are new developments, for example, using Multi-Axis Differential Optical Absorption Spectroscopy (MAX-DOAS) [Irie et al., 2011] or radiosondes [Sluis et al., 2010]. As a consequence, linking $\mathrm{NO}_{2}$ surface concentration to the integrated content in the $\mathrm{ABL}$ requires an hypothesis on $\mathrm{NO}_{2}$ vertical distribution in the ABL.

[4] To bridge this gap, some authors have supposed a homogeneous distribution in the ABL [e.g. Boersma et al., 2008], while others make use of $\mathrm{NO}_{2}$ profiles from chemistry-transport models [e.g. Lamsal et al., 2008]. This makes it possible to relate the year-to-year and seasonal variability of $\mathrm{NO}_{2}$ observed at ground level and from space, from which monthly $\mathrm{NO}_{x}$ emissions can be estimated. However, neither of these solutions enables to monitor emissions at a shorter time scale, as point to point comparison between surface and space-borne observations show very large dispersion over cities. Yet, estimating daily $\mathrm{NO}_{x}$ emissions is mandatory to monitor the impact of cities on regional air quality.

[5] In order to understand why previous studies experienced difficulties over urban areas, we have compared $\mathrm{NO}_{2}$ surface concentrations with ground-based $\mathrm{NO}_{2}$ integrated content and ABL depth measurements over the welldocumented area of Paris. Surface $\mathrm{NO}_{2}$ observations are provided by the air quality network AIRPARIF (http:/www. airparif.asso.fr/) that include surface stations and altitude measurements (300 m elevation). The $\mathrm{NO}_{2}$ integrated content is obtained by a zenith-sky UV-visible (UV-vis) light spectrometer located in Paris city center at the University Pierre et Marie Curie (UPMC) Qualair facility, along with an aerosol lidar giving ABL height information. This experimental setup provided us with a unique dataset over several years to analyze $\mathrm{NO}_{2}$ behavior in urban conditions.

[6] $\mathrm{NO}_{2}$ observations from the air quality network and from the UV-vis spectrometer will be presented in Section 2, and $\mathrm{NO}_{2}$ variability will be analyzed to underline vertical gradients in the urban ABL. Adding ABL depth measurements from the aerosol lidar, a statistical relationship between $\mathrm{NO}_{2}$ surface concentration and integrated content in the $\mathrm{ABL}$ will be derived in Section 3. The unexpected form of this relationship and its consequences in terms of $\mathrm{NO}_{2}$ vertical mixing and satellite validation will be discussed in Section 4. 


\section{2. $\mathrm{NO}_{2}$ Variability Over Paris}

\section{1. $\mathrm{NO}_{2}$ Surface Concentrations}

[7] Hourly measurements of $\mathrm{NO}_{2}$ surface concentrations provided by Paris air quality network (AIRPARIF) are using the standard in situ $\mathrm{NO}_{x}$ analyzers prescribed by air quality regulations. $\mathrm{NO}_{2}$ is measured after reduction to $\mathrm{NO}$ on a heated Molybdenum converter, which is known to convert efficiently other oxidized nitrogen species $\left(\mathrm{NO}_{z}\right)$ like $\mathrm{HNO}_{3}$ and peroxyacetyl nitrate. $\mathrm{NO}_{2}$ concentrations can thus be overestimated by as much as $50 \%$, depending on photochemical activity, as confirmed during urban campaigns [Dunlea et al., 2007] or in rural stations [Ordóñez et al., 2006]. The impact of this bias will be discussed in Section 4 .

[8] The six urban background stations in Paris are averaged to estimate the mean hourly $\mathrm{NO}_{2}$ surface concentration in the city $\left(C_{g M}\right)$. Figure 1(a) presents the median diurnal and seasonal cycle of $C_{g M}$, calculated over 6 years (2005-2010). The daily cycle of $\mathrm{NO}_{2}$ surface concentration is dominated by $\mathrm{NO}_{x}$ emissions variability, that is, by traffic, which represents half of $\mathrm{NO}_{x}$ emissions in Paris region. During traffic peak periods (07-10 and 17-20 LT), $\mathrm{NO}_{2}$ concentrations are mainly driven by emission level and by vertical dilution, that is, by ABL depth (this is why the evening peak on Figure 1(a) is much less visible in summer). Outside those peak periods, an off-peak regime exists around noon, where the seasonal cycle of $\mathrm{NO}_{x}$ chemical lifetime and $\mathrm{ABL}$ depth are the dominant parameters.

\section{2. $\mathrm{NO}_{2}$ Vertical Gradient}

[9] AIRPARIF runs a station at Eiffel Tower top (300 m above ground level) that allows to monitor the vertical gradient in the lower ABL. The diurnal and seasonal variability of the relative difference $\left(C_{g M}-C_{E T}\right) / C_{g M}$, where $C_{E T}$ is the concentration at tower top, are presented on Figure 1(b). The difference is always positive, meaning there is less $\mathrm{NO}_{2}$ in altitude. Yet, concentrations could be expected to grow with altitude as NO emissions are converted to $\mathrm{NO}_{2}$ by reaction with ozone. This means that most of $\mathrm{NO}$ is converted below the tower top, which is confirmed by looking at NO gradient values (not shown here). Then, $\mathrm{NO}_{2}$ concentrations decrease with altitude due to dilution and chemical conversion to $\mathrm{NO}_{z}$.

[10] During the night, except in summer, the vertical gradient is very large as the tower top is often out of the nocturnal ABL. The large nighttime variations from one month to the next are due to ground-level variability as they do not appear on the absolute difference (not shown here). During daytime, the vertical gradient quickly decreases by a factor of two about $2-3 \mathrm{~h}$ after sunrise, when the convective ABL starts rising and reaches the tower top. However, even during the morning ABL growth, when the vertical mixing is most efficient, there is still at least $25 \%$ less $\mathrm{NO}_{2}$ at the tower top than at ground level. For comparisons with integrated content measurements, this means that the homogeneous ABL hypothesis will lead to a large overestimation of the columns.

\section{3. $\mathrm{NO}_{2}$ Integrated Content}

[11] The Système d'analyse par Observation au Zénith (SAOZ), a zenith-sky UV-visible spectrometer [Pommereau and Goutail, 1988], has been monitoring $\mathrm{NO}_{2}$ in Paris (a) $\mathrm{NO}_{2}$ surface concentration

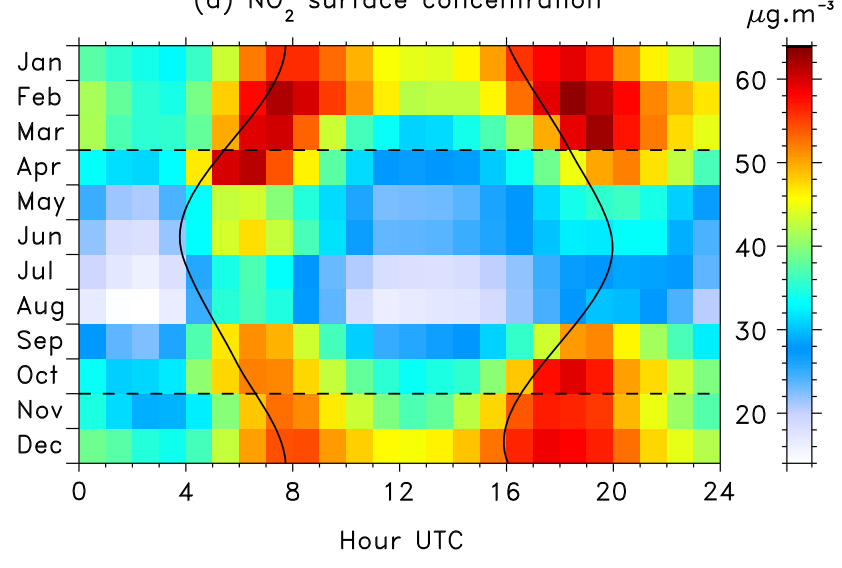

(b) $\mathrm{NO}_{2}$ conc. diff. (surface - Eiffel)/surface

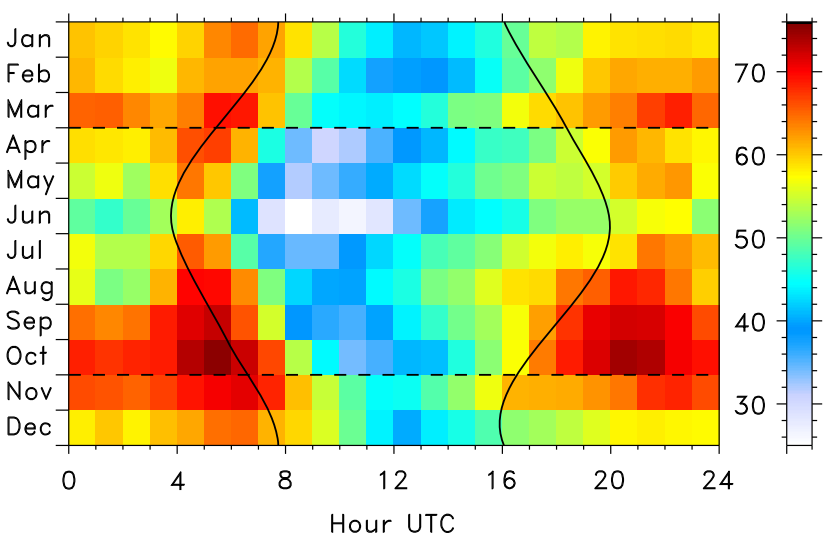

(c) SAOZ NO${ }_{2}$ tropospheric column $10^{15} \mathrm{~cm}^{-2}$

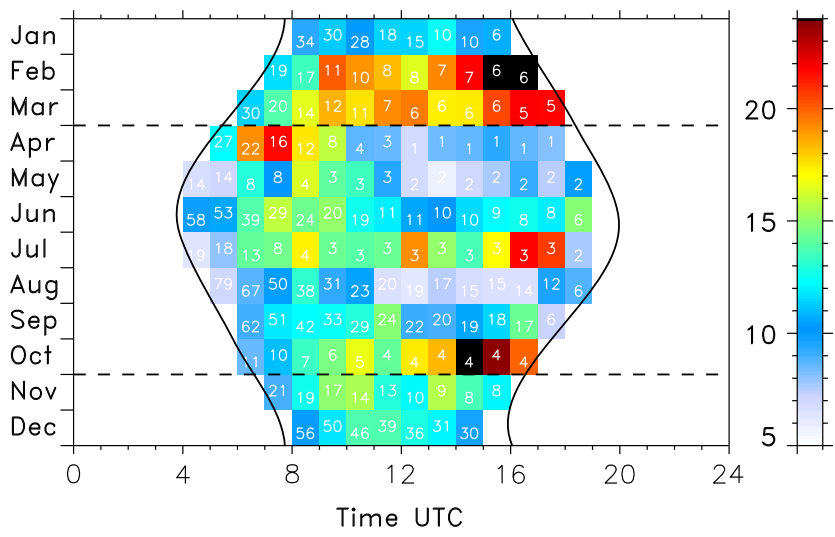

Figure 1. $\mathrm{NO}_{2}$ median diurnal cycle (horizontal reading) and median seasonal cycle (vertical reading): (a) surface concentration in Paris, (b) relative difference with Eiffel Tower concentration, and (c) tropospheric column. Data from 2005 to 2010 were included. White digits give the number of SAOZ observations in the median column. Solid lines show sunrise and sunset time, dashed lines show the change of local time from $\mathrm{UTC}+1$ in winter to $\mathrm{UTC}+2$ in summer.

from January 2005 as part of the observation platform Qualair (http://qualair.aero.jussieu.fr/) on the UPMC Jussieu campus. Every 15 minutes, a spectrum of the sunlight diffused in the zenith direction is measured and $\mathrm{NO}_{2}$ total 
slant column density (SCD) is retrieved using Differential Optical Absorption Spectroscopy (DOAS) in $\mathrm{NO}_{2}$ absorption bands at $410-427$ and $433-530 \mathrm{~nm}$.

[12] The SCD stratospheric part is estimated using measurements at dawn (Solar Zenith Angle $>90^{\circ}$ ) when the light path is much longer in the stratosphere and absorption by tropospheric $\mathrm{NO}_{2}$ can be neglected. This hypothesis is not entirely true during a pollution episode so the median of the last 3 days is used instead of the current day measurement. The dawn column is corrected for $\mathrm{NO}_{2}$ daily cycle in the stratosphere using a stratospheric chemistry model. From a 1-year run of the Single Layer Isentropic Model of Chemistry and Transport (SLIMCAT), monthly averaged coefficients of the ratio between stratospheric SCD at various time of the day and at dawn were derived. After subtracting the stratospheric $\mathrm{SCD}$, the remaining tropospheric SCD is converted to a vertical column density (VCD noted $\Omega$ ) by division with an air mass factor (AMF).

[13] The SAOZ AMF is the average of the daily AMF calculated during the Cabauw Intercomparison campaign for Nitrogen Dioxide measuring Instruments (CINDI) in Netherlands, using $\mathrm{NO}_{2}$ and aerosol extinction profiles performed by a Multi-Axis UV-vis spectrometer (MAX-DOAS) Clémer et al., 2010 personal communication) [Piters et al.., 2012]. To limit the possible AMF underestimation due to multiple scattering in the larger aerosol optical depths (AOD) observed in Paris, the $550-600 \mathrm{~nm}$ sky color ratio is used to discard cloudy and high-AOD spectra. The threshold value was tuned using coincident measurements of the collocated Aerosol Robotic Network sunphotometer so as to reject AOD values greater than 0.35 at $440 \mathrm{~nm}$ [Dieudonné, 2012].

[14] The main sources of error are the possible overestimation of the stratospheric SCD and AMF underestimation, but they have opposite effects on the tropospheric VCD and will partly cancel each other. For another zenith-sky DOAS in Shanghai, Chen et al. [2009] estimated that the total uncertainty on tropospheric VCD can reach $50 \%$ for small VCD $\left(<10.10^{15} \mathrm{~cm}^{-2}\right)$. However, most observations over Paris are above this value, and the total uncertainty estimated by Chen et al. [2009] is around 30-40\%.

[15] The median diurnal and seasonal cycle of $\mathrm{NO}_{2}$ tropospheric VCD retrieved over Paris are presented on Figure 1(c). Over a polluted area like Paris, the tropospheric VCD (latter on just called column) is expected to be dominated by the ABL contribution. However, columns and surface concentrations are expected to show a very different behavior: in a growing ABL, vertical dilution will reduce surface concentrations, while columns can still increase as $\mathrm{NO}_{2}$ keeps accumulating in the ABL. Indeed, the column daily maximum in Paris occurs in late morning instead of during the morning traffic peak.

\section{Concentration/Column Relationship}

\subsection{Boundary Layer Depth Observations}

[16] In order to derive a relationship between $\mathrm{NO}_{2}$ surface concentration and integrated content, we used measurements of ABL depth provided by the Qualair $532 \mathrm{~nm}$ aerosol lidar [Dieudonné, 2012]. ABL top can be determined above a $180 \mathrm{~m}$ height using a gradient detection method as in Menut et al. [1999]. To match the time resolution of in situ observations, this method is applied on the hourly averaged signal. The dataset used in this paper spans over 20 months, from July 2009 to February 2011, and covers around 50\% of the days, generally from 9 to 18 LT. Observations occurring less than $3 \mathrm{~h}$ after sunrise are discarded so as to limit to the $\mathrm{NO}_{2}$ off-peak conditions. This leaves 821 coincident measurements of $\mathrm{NO}_{2}$ surface concentration, $\mathrm{NO}_{2}$ column, and $\mathrm{ABL}$ depth. As afternoons are generally more cloudy, limiting SAOZ observations, only $21 \%$ of points occur after 15 UTC $-10 \%$ after 16 UTC - so that this data set mostly corresponds to the developing ABL.

\subsection{Statistical Treatment}

[17] The scatter plot of $\mathrm{NO}_{2}$ column as a function of the surface concentration is presented on Figure 2, with a color code for ABL depth. When the ABL is deeper, the $\mathrm{NO}_{2}$ column $\Omega$ grows faster along with the surface concentration $C_{g M}$. To investigate this dependency, observations are split into eight classes following ABL depth values (Table 1a). The eight correlation coefficients between $C_{g M}$ and $\Omega$ lie between 0.69 and 0.77 , indicating a rather homogeneous behavior for similar values of ABL depth. In each class, a linear fit of $\Omega$ versus $C_{g M}$ is performed. The resulting fit lines are plotted on Figure 2, while Table 1(a) gives the slope $(p)$ and intercept $(q)$ values. As expected from previous observations, $p$ increases with growing ABL depth.

[18] These slopes and intercepts values are then plotted as a function of the median ABL depth $h$ in each class (Figure 3) and a linear fit of $p$ and $q$ versus $h$ is performed (results in Table 1b). The slopes $p$ increase in a remarkably linear way with ABL depth, leading to a correlation coefficient of 0.98 . This means that ABL depth is a main parameter to account for slope variability. However, the linear fit has a nonzero intercept, which means that the integrated content is not directly proportional to the product $h C_{g M}$ (homogeneous column) but includes a term independent of ABL depth as will be further discussed in the next section.

[19] The intercepts $q$ tend to decrease while ABL depths increase, but their behavior appears slightly different in the $0.6-1.6 \mathrm{~km}$ height range. Observations in these classes often correspond to the late morning period when the

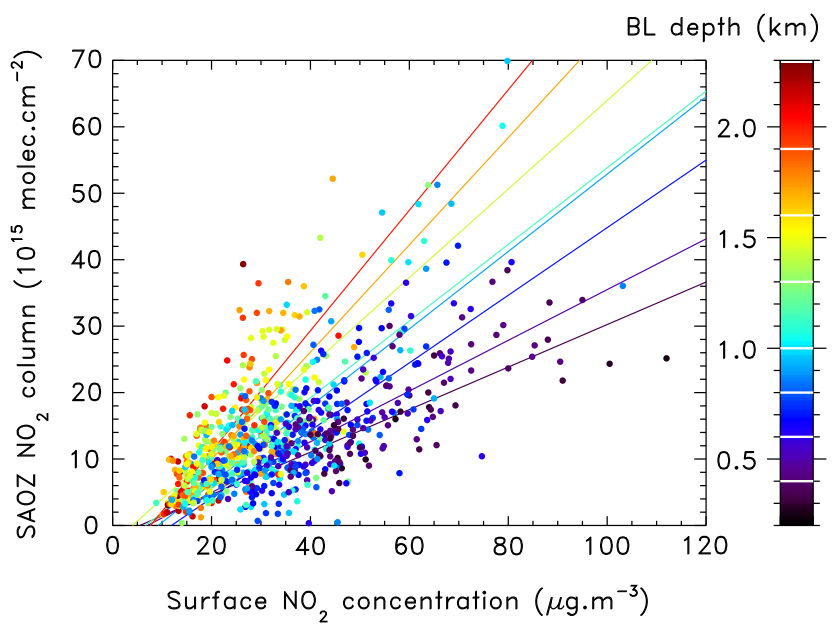

Figure 2. $\mathrm{NO}_{2}$ tropospheric $\mathrm{VCD} \Omega$ from the $\mathrm{SAOZ}$ as a function of $\mathrm{NO}_{2}$ surface concentration $C_{g M}$. Points are colored according to the lidar derived ABL depth $h$. 
Table 1. (a) Classes of ABL Depth With Number of Points $N$, Correlation Coefficient $r$ and Results of the Linear Fit $\Omega / K=p \times C_{g M}+q$ Between $\mathrm{NO}_{2}$ Tropospheric VCD $\Omega$ and Surface Concentration $C_{g M}$ for Each Class ${ }^{\mathrm{a}}$. (b) Correlation Coefficient and Results of the Linear Fit $p$ or $q=a \times h+b$ Between the Slopes $p$ or Intercepts $q$ and the Median ABL Depth $h$ in Each Class ${ }^{\mathrm{b}}$

\begin{tabular}{|c|c|c|c|c|}
\hline \multicolumn{5}{|c|}{ (a) Linear fit $\Omega / K=p \times C_{g M}+q$} \\
\hline $\begin{array}{l}h \\
(\mathrm{~km})\end{array}$ & $N$ & $r$ & $\begin{array}{c}\text { Slope } p \\
\left(\mathrm{~cm}^{-2} / \mu \mathrm{g} \cdot \mathrm{m}^{-3}\right)\end{array}$ & $\begin{array}{l}\text { Intercept } q \\
\left(\mathrm{~cm}^{-2}\right)\end{array}$ \\
\hline$<0.4$ & 47 & 0.77 & $0.260 \pm 0.044$ & $-2.107 \pm 2.295$ \\
\hline $0.4-0.6$ & 93 & 0.76 & $0.289 \pm 0.028$ & $-1.718 \pm 1.244$ \\
\hline $0.6-0.8$ & 135 & 0.74 & $0.388 \pm 0.035$ & $-4.721 \pm 1.286$ \\
\hline $0.8-1.0$ & 119 & 0.75 & $0.448 \pm 0.071$ & $-4.232 \pm 2.106$ \\
\hline $1.0-1.3$ & 135 & 0.76 & $0.443 \pm 0.058$ & $-3.050 \pm 1.550$ \\
\hline $1.3-1.6$ & 124 & 0.72 & $0.503 \pm 0.053$ & $-1.857 \pm 1.200$ \\
\hline $1.6-1.9$ & 105 & 0.75 & $0.616 \pm 0.078$ & $-4.732 \pm 1.542$ \\
\hline$>1.9$ & 63 & 0.69 & $0.692 \pm 0.101$ & $-5.314 \pm 1.753$ \\
\hline Total & 821 & & & \\
\hline
\end{tabular}

(b) Linear fit $p$ or $q=a \times h+b$

\begin{tabular}{lrrr}
\hline & \multicolumn{1}{c}{$r$} & \multicolumn{1}{c}{ Slope $a$} & \multicolumn{1}{c}{ Intercept $b$} \\
\hline Slopes $p$ & 0.98 & $0.244 \pm 0.038$ & $0.184 \pm 0.034$ \\
Intercepts $q$ & -0.55 & $-0.337 \pm 0.323$ & $-0.512 \pm 0.297$ \\
\hline
\end{tabular}

${ }^{\mathrm{a}} \mathrm{K}=1.31 .10^{15}$ is a constant factor coming from unit conversion between $h$ in $\mathrm{km}, C_{g M}$ in $\mu \mathrm{g} \cdot \mathrm{m}^{-3}$ and $\Omega$ in $\mathrm{cm}^{-2}$.

${ }^{\mathrm{b}}$ The first step fits are least-square $(\mathrm{Y} \mid \mathrm{X})$ without error. The second step fits are least-square $(\mathrm{Y} \mid \mathrm{X})$ using uncertainties on $p$ and $q$ as Y-error.

ABL grows rapidly. At this time, the entrainment of large amounts of clean air in the ABL could explain the different behavior. Anyway, the correlation coefficient being only -0.55 , ABL depth is not the only parameter influencing the intercepts.

[20] To discuss the dependency of $\mathrm{NO}_{2}$ column against ABL depth and $\mathrm{NO}_{2}$ surface concentration, results of the

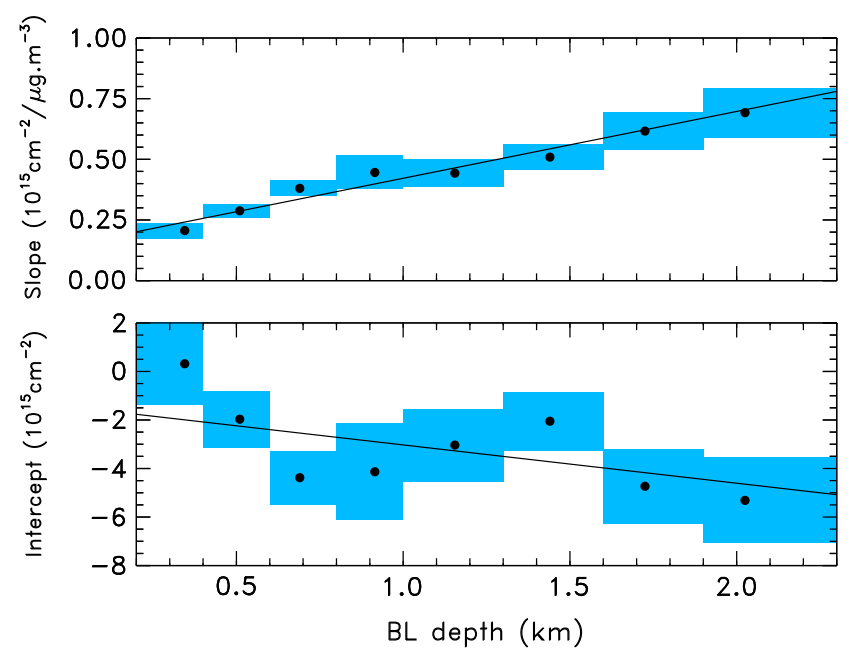

Figure 3. Slopes $p$ (up) and intercepts $q$ (down) obtained by fitting linearly $\mathrm{NO}_{2}$ tropospheric VCD against surface concentration for each class of ABL depth (abscissa is median ABL depth $h$ in the class). Blue rectangles show uncertainties on slopes and intercept in the $y$-direction and class width in the $x$-direction. Black lines are results of the linear fit with error. slopes and intercepts fits are combined to create a bilinear model as follows:

$$
\begin{aligned}
\frac{\Omega}{K} & =\overbrace{(0.244 h+0.184)}^{\text {slopes fit } p(h)} \times C_{g M} \overbrace{-(0.337 h+0.512)}^{\text {intercepts fit } q(h)} \\
& =0.244 h\left(C_{g M}-1.38\right)+0.184\left(C_{g M}-2.83\right),
\end{aligned}
$$

where $K$ is a unit conversion factor (see note (a) in Table 1).

\section{Discussion}

[21] Results from Section 2 underline the existence of strong vertical gradients of $\mathrm{NO}_{2}$ concentration in Paris urban ABL. Moreover, the large diurnal and seasonal variability results in very different behaviors for $\mathrm{NO}_{2}$ surface concentrations and columns. As a consequence, the homogeneous ABL hypothesis often used to calculate DOAS AMF and for satellite validation appears unrealistic over high-emission areas. Yet, we showed in Section 3 that in spite of large uncertainties on $\mathrm{NO}_{2}$ observations, a robust relationship between $\mathrm{NO}_{2}$ surface concentration and column can be established, using only ABL depth as an ancillary parameter. This relationship covers all seasons and describes $\mathrm{NO}_{2}$ vertical mixing over Paris in the daytime developing ABL.

[22] Equation (1b) shows that $\mathrm{NO}_{2}$ column depends on an effective surface concentration lower than the measured concentration by $1.38 \pm 1.32 \mu \mathrm{g} . \mathrm{m}^{-3}$ in the first term and $2.83 \pm 1.61 \mu \mathrm{g} . \mathrm{m}^{-3}$ in the second one. Given the uncertainties, both values are compatible with a mean value around $2 \pm 1 \mu \mathrm{g} \cdot \mathrm{m}^{-3}$. This could be interpreted as a bias in $\mathrm{NO}_{2}$ measurements due to $\mathrm{NO}_{z}$ interferences in standard $\mathrm{NO}_{x}$ analyzers. The large uncertainties would then result from interference variability, following local photochemical activity and nonlocal production (import from Benelux and Ruhr regions). Another explanation could be that groundlevel stations do not represent the true urban background because horizontal dilution is not complete.

[23] The second term of equation (1b) is a product between the effective concentration and a fixed height $h_{0}=$ $184 \pm 34 \mathrm{~m} . h_{0}$ is too large to be the actual depth of the surface layer but can be interpreted as an effective mixing height, describing turbulent transfer processes from the surface layer to the mixed part of the ABL. The first term of equation $(1 \mathrm{~b})$ corresponds to the homogeneous $\mathrm{ABL}$ column but with a $24.4 \pm 3.8 \%$ factor, which means that the average ABL concentration is only one fourth of the groundlevel effective concentration. According to Stull [1988], the entrainment zone occupies in average $40 \%$ of the convective ABL, with concentrations being in average half of their mixed layer value, so that entrainment could explain only a 0.8 factor. Correcting for $\mathrm{NO}_{z}$ interferences would lead to concentrations smaller by a 0.5 to 1.0 factor, depending on the hour and season [Dunlea et al., 2007; Ordóñez et al., 2006]. The slopes $p$ would then increase by an average $1 / 0.75=1.3$ factor, resulting in an ABL average to surface concentration ratio around $33 \%$. The effect of SAOZ errors is probably much smaller due to the partly canceling errors.

[24] To account for a 0.33 factor, $\mathrm{NO}_{2}$ has to be efficiently removed before it can reach the ABL upper levels. Photochemical losses (conversion to $\mathrm{NO}_{z}$ ) are unlikely to be responsible. Indeed, $\mathrm{NO}_{x}$ lifetime estimations available in the literature are all above $1 \mathrm{~h}$ (Kondo et al. [2008] and references therein), while the vertical mixing time is 10 to 
20 min [Stull, 1988]. However, this time is long enough to allow part of the $\mathrm{NO}_{2}$ to be pushed away from the city center by the wind. Turbulent dispersion modeling studies like Vinuesa and Galmarini [2009] confirm that horizontal export could create such a vertical gradient, even at moderate wind speeds.

[25] Simple models with linear or exponential concentration profiles in the ABL were also tested but both lead to large overestimations of the columns and neither can reproduce their seasonal variability [Dieudonné, 2012]. Adding a surface layer with higher concentrations, as suggested by the second term of equation (1b), may help solving the problem, but then, we lack information to conclude on the exact profile shape. Further analysis of our data will thus investigate the influence of wind speed, try to quantify the relative contribution of the dynamical and chemical processes and refine the error budget. However, urban profile measurements are urgently needed to bring more information on the profile shape and support future modeling studies.

\section{Conclusions}

[26] In this paper, we showed that strong vertical gradients of $\mathrm{NO}_{2}$ concentration exist in Paris daytime urban ABL. This makes the uniform profile hypothesis often used in satellite retrieval process and validation irrelevant over high-emission areas. As an alternative, we used multiseasonal observations from Paris air quality network, a ground-based UV-visible spectrometer and an aerosol lidar to develop an empirical relationship between $\mathrm{NO}_{2}$ surface concentration, $\mathrm{NO}_{2}$ integrated content, and $\mathrm{ABL}$ depth.

[27] This relationship enables the use of satellite observations to derive surface concentrations over Paris and is very likely exportable to other cities. Indeed, Paris is $150 \mathrm{~km}$ away from the sea and has a low orography (below $200 \mathrm{~m}$ above sea level) so that no sea or mountain-breeze effects would affect the mixing processes taking place in the urban $\mathrm{ABL}$. The values of the relationship parameters might have to be adjusted over other cities, but this will give insight into the relative contributions of the different processes involved.

[28] Application to satellite observations will be the object of future work, particularly for morning satellite instruments like SCIAMACHY (Scanning Imaging Absorption Spectrometer for Atmospheric Chartography), and GOME-2 (Global Ozone Monitoring Experiment-2). Indeed, we showed in Section 2 that their overpass time coincides with $\mathrm{NO}_{2}$ maximum accumulation in the ABL, making them best suited to monitor $\mathrm{NO}_{x}$ emissions when their resolution will be improved. Alternatively, to avoid a heavy network setting, measurements of the integrated column may be implemented in city centers. Our results also show that future observation campaigns dedicated to urban pollution should put a priority on measuring urban concentrations profiles in addition to horizontal transects, as both vertical and horizontal gradients matter for satellite validation.

[29] Acknowledgments. The authors would like to thank AIRPARIF for the in situ observations as well as IPSL and UPMC for supporting the Qualair station.

\section{References}

Boersma, K. F., et al. (2008), Validation of OMI tropospheric $\mathrm{NO}_{2}$ observations during INTEX-B and application to constrain $\mathrm{NO}_{x}$ emissions over the eastern United States and Mexico, Atmos. Environ, 42 (19), 4480-4497, doi: 10.1016/j.atmosenv.2008.02.004.

Chen, D., B. Zhou, S. Beirle, L. M. Chen, and T. Wagner (2009), Tropospheric $\mathrm{NO}_{2}$ column densities deduced from zenith-sky DOAS measurements in Shanghai, China, and their application to satellite validation, Atmos. Chem. Phys., 9(11), 3641-3662, doi:10.5194/acp-9-3641-2009.

Dieudonné, E. (2012), Multi-instrumental analysis of the influence of boundary layer depth variability on the vertical distribution of nitrogen oxides in Paris region, Ph.D. thesis, UPMC, France, in French.

Dunlea, E. J., et al. (2007), Evaluation of nitrogen dioxide chemiluminescence monitors in a polluted urban environment, Atmos. Chem. Phys., 7 (10), 2691-2704, doi:10.5194/acp-7-2691-2007.

Irie, H., H. Takashima, Y. Kanaya, K. F. Boersma, L. Gast, F. Wittrock, D. Brunner, Y. Zhou, and M. Van Roozendael (2011), Eight-component retrievals from ground-based MAX-DOAS observations, Atmos. Meas. Tech., 4(6), 1027-1044, doi:10.5194/amt-4-1027-2011.

Kondo, Y., et al. (2008), Formation and transport of oxidized reactive nitrogen, ozone, and secondary organic aerosol in Tokyo, J. Geophys. Res., 113(D12), D21,310, doi:10.1029/2008JD010134.

Lamsal, L. N., R. V. Martin, A. van Donkelaar, M. Steinbacher, E. A. Celarier, E. Bucsela, E. J. Dunlea, and J. P. Pinto (2008), Ground-level nitrogen dioxide concentrations inferred from the satelliteborne ozone monitoring instrument, 113, D16,308, doi: 10.1029/ 2007JD009235.

Menut, L., C. Flamant, J. Pelon, and P. H. Flamant (1999), Urban boundarylayer height determination from lidar measurements over the Paris area, Appl. Opt., 38(6), 945-954.

Ordóñez, C., A. Richter, M. Steinbacher, C. Zellweger, H. Nüß, J. P. Burrows, A. S. H. Prévôt (2006), Comparison of 7 years of satelliteborne and ground-based tropospheric $\mathrm{NO}_{2}$ measurements around Milan, Italy, J. Geophys. Res., 111(D10), 5310, doi:10.1029/2005JD006305.

Piters, A. J. M. et al. (2012), The Cabauw Intercomparison campaign for Nitrogen Dioxide measuring Instruments (CINDI): design, execution, and early results, Atmos. Meas. Tech., 5(2), 457-485, doi:10.5194/amt5-457-2012.

Pommereau, J. P., and F. Goutail (1988), $\mathrm{O}_{3}$ and $\mathrm{NO}_{2}$ ground-based measurements by visible spectrometry during arctic winter and spring 1988 , Geosphys. Res. Lett., 15, 891-894, doi:10.1029/GL015i008p00891.

Sluis, W. W., M. A. F. Allaart, A. J. M. Piters, and L. F. L. Gast (2010), The development of a nitrogen dioxide sonde, Atmos. Meas. Tech., 3(6), 1753-1762, doi:10.5194/amt-3-1753-2010.

Stull, R. B. (1988), An Introduction to Boundary Layer Meteorology, in Convective Mixed Layer, Kluwer Academic Publishers, New York.

Vinuesa, J.-F., and S. Galmarini (2009), Turbulent dispersion of nonuniformly emitted passive tracers in the convective boundary layer, Bound.-Layer Meteorol., 133, 1-16, doi:10.1007/s10546-009-9416-0. 